\title{
Silencing of genes at nontelomeric sites in yeast is controlled by sequestration of silencing factors at telomeres by Rap1 protein
}

\author{
Stéphane Marcand, ${ }^{1,2}$ Stephen W. Buck, ${ }^{1}$ Paolo Moretti, ${ }^{1}$ Éric Gilson, ${ }^{2}$ and David Shore ${ }^{1,3,4}$ \\ ${ }^{1}$ Department of Microbiology, College of Physicians and Surgeons of Columbia University, New York, New York 10032 \\ USA; ${ }^{2}$ Laboratoire de Biologie Moléculaire et Cellulaire de l'Ecole Normale Supérieure de Lyon, Unité Mixte de Recherche \\ 49 du Centre National de la Recherche Scientifique et de l'École Normale Supérieure de Lyon, 69364 Lyon Cédex 07, France
}

Rap1p binds to silencer elements and telomeric repeats in yeast, where it appears to initiate silencing by recruiting Sir3p and Sir4p to the chromosome through interactions with its carboxy-terminal domain. Sir3p and Sir4p interact in vitro with histones $\mathrm{H} 3$ and $\mathrm{H} 4$ and are likely to be structural components of silent chromatin. We show that targeting of these Sir proteins to the chromosome is sufficient to initiate stable silencing either at a silent mating-type locus lacking a functional silencer element or at a telomere in a strain in which the Rap1p carboxy-terminal silencing domain has been deleted. Silencing by Sir protein targeting can also be initiated at a telomere-proximal site $(A D H 4)$, but is much weaker at an internal chromosomal locus (LYS2). Strikingly, deletion of the Rap1p silencing domain, which abolishes telomeric silencing, improves targeted silencing at LYS2 by both Sir3p and Sir4p, while weakening the silencing activity of these proteins at or near a telomere. This effect may result from the release of Sir proteins from the telomeres, thus increasing their effective concentration at other chromosomal sites. We suggest that telomeres and Rap1p serve a regulatory role in sequestering Sir proteins at telomeres, controlling silencing at other loci in trans and preventing indiscriminate gene silencing throughout the genome.

[Key Words: Sir proteins; mating type; silencing; Rap1; telomere position effect]

Received February 22, 1996; revised version accepted April 23, 1996.

The yeast Saccharomyces cerevisiae uses a form of position-effect regulation, commonly referred to as transcriptional silencing (Brand et al. 1985), to control the expression of genes that determine mating type (for review, see Laurenson and Rine 1992). A very similar but less stable form of repression is also observed when genes are placed near telomeres in yeast (Gottschling et al. 1990; Aparicio et al. 1991), suggesting that silencing may play a more general role in regulating gene expression in this organism (for review, see Shore 1995). Many of the properties of silencing in yeast are reminiscent of position-effect variegation in Drosophila, and recent molecular studies (Hecht et al. 1995) suggest that silencing in yeast may be analogous to heterochromatin formation in more complex eukaryotes.

A number of cis- and trans-acting elements involved in silencing have now been identified and characterized in some detail. The silencer elements that flank the two silent mating-type loci ( $H M L$ and $H M R$ ) all contain an autonomously replicating sequence (ARS) consensus se-

\footnotetext{
${ }^{3}$ Present address: Départment de Biologie Moléculaire, Université de Genève, Sciences II, CH-1211 Genève 4, Switzerland.

${ }^{4}$ Corresponding author.
}

quence (ACS, or A site), which is bound by the origin recognition complex (ORC) (Bell and Stillman 1992; Diffley and Cocker 1992). In addition, each silencer contains binding sites for Raplp (the E site), Abflp (the B site), or both (Brand et al. 1987; Shore and Nasmyth 1987; Shore et al. 1987; Buchman et al. 1988; Kimmerly et al. 1988; Mahoney et al. 1991; Boscheron et al. 1996). On the other hand, telomeres contain multiple Raplp-binding sites within the terminal poly $\left.\mid \mathrm{C}_{1-3} \mathrm{~A}\right)$ tracts (Longtine et al. 1989; Gilson et al. 1993) that play a role in telomeric silencing (Kyrion et al. 1993; Buck and Shore 1995). Telomere-associated repeat sequences also contain ACS elements and Abflp-binding sites (Biswas and Biswas 1990; Louis et al. 1994), but their role in telomeric silencing, if any, is unclear. Genetic studies have demonstrated that individual ORC subunits (Bell et al. 1993, 1995; Foss et al. 1993; Micklem et al. 1993) and Abflp (Loo et al. 1995) do play a role in silencing at HM matingtype loci, whereas Raplp functions in silencing at both HM loci and telomeres (Kurtz and Shore 1991; Sussel and Shore 1991; Kyrion et al. 1993; Moretti et al. 1994).

In addition to the genes encoding silencer- and telomere-binding proteins, three silent information regulator genes (SIR2, SIR3, and SIR $\overline{4})$ are réquired for silencing at both HM loci and telomeres (Rine and Herskowitz 
1987; Aparicio et al. 1991). A fourth SIR gene, SIR1, is required for stable silencing at $H M$ loci (Pillus and Rine 1989; Stone et al. 1991), but plays no role at telomeres where position-effect repression is unstable or variegated (Aparicio et al. 1991). Sirlp appears to act upstream of the other Sir proteins at $H M$ silencers, through interactions with ORC, to ensure that silencing is reestablished efficiently after each cell division (Chien et al. 1993). Both Sir3p and Sir4p interact with Raplp in the two-hybrid system (Moretti et al. 1994), suggesting a model in which silencing is initiated by the recruitment of a complex of these Sir proteins to the chromosome by Raplp. This complex may polymerize along the chromatin fiber through a network of Sir-Sir interactions /Chien et al. 1991; Moretti et al. 1994), leading to the formation of a heterochromatin-like structure through direct interactions of Sir3p and Sir $4 p$ with the basic amino-terminal tails of histones $\mathrm{H} 3$ and $\mathrm{H} 4$ (Hecht et al. 1995).

One prediction of this model for the initiation of silencing is that direct targeting of either Sir3p or Sir4p to the chromosome might be sufficient to bypass the requirement for Raplp and other silencer-binding proteins and establish repression. However, previously we found that Gal4p DNA-binding domain (Gbd) hybrids with either Sir2p, Sir3p, or Sir4p failed to establish significant repression at an $H M R$ locus containing Gal4p DNAbinding sites, whereas a Gbd-Sirlp hybrid did do so (Chien et al. 1993). We noted, although, that expression of the Gbd-Sir3p and Gbd-Sir4p hybrids had a strong derepressing effect on a normally silenced telomeric reporter gene that contained no Gal4p-binding sites. Because it is known that transcriptional silencing can be very sensitive to the dosage of SIR genes (Marshall et al. 1987; Sussel and Shore 1991; Renauld et al. 1993; Sussel et al. 1993), we tested the effect of the identical GbdSir3p and Gbd-Sir4p fusions when expressed at a lower level, using the RAP1 promoter instead of the strong $A D H 1$ promoter, and a low copy number centromerecontaining plasmid. Here we show that Gbd-Sir3p and Gbd-Sir $4 p$ hybrids can act as strong initiators of silencing when targeted to the $H M R$ locus or to sites at or near a telomere, even in cells containing a RAP1 carboxyterminal deletion that abolishes normal telomeric silencing. At an internal (nontelomeric) site, silencing was observed only with Gbd-Sir4p in wild-type $\left(R A P 1^{+}\right)$ cells, but it was weak. Silencing by Gbd-Sir hybrids at an internal site was greatly improved, however, by deletion of the Raplp carboxy-terminal domain. We argue that Raplp bound at telomeres acts as a "sink" or "reservoir" for Sir proteins in the nucleus, thus preventing the inappropriate silencing of genes elsewhere in the chromosome. This model may have important implications for the effect of telomere length and telomeric silencing on gene regulation in higher eukaryotes.

\section{Results}

$G b d-S i r 3 p$ and $G b d-S i r 4 p$ hybrids restore repression when targeted to mutated HMR-E silencers

To test the ability of the new Gbd-Sir3p and Gbd-Sir4p constructs to establish transcriptional silencing at $H M R$, we used strains containing Gal4p-binding sites $\left(\mathrm{UAS}_{\mathrm{G}}\right)$ inserted at mutated silencers (Chien et al. 1993; Buck and Shore 1995). In the first two strains, the HMR-E silencer was deleted for the Raplp-binding site (element $E$ ) and either the ORC-binding site (A) or the Abflp-binding site $(B \mid$. In the third strain, all three silencer regulatory sites $(A, E$, and $B)$ are deleted and replaced by $U_{A S}$ sites. All three of these mutated silencers are completely defective in repression as judged by Northern analysis of steady-state a1 mRNA levels (Buck and Shore 1995).

We first tested the ability of Gbd-Sir3p and Gbd-Sir4p hybrids to silence the $a 1$ gene normally present at the $H M R$ locus in a strain in which two HMR-E silencer elements (A and $E$ ) were deleted and replaced by $\mathrm{UAS}_{\mathrm{G}}$ sites. As shown in Figure 1, the expression of Gbd-Sir3p or Gbd-Sir $4 p$ resulted in a very strong reduction in steady-state a1 mRNA with the $\mathrm{UAS}_{\mathrm{G}}$-containing silencer. The Gbd alone control plasmid failed to confer repression. A control strain lacking $\mathrm{UAS}_{\mathrm{G}}$ sites at $H M R$ also remained derepressed in the presence of Gbd-Sir3p or Gbd-Sir $4 p$, demonstrating that the site of action for the hybrid proteins is the mutated silencer.

A
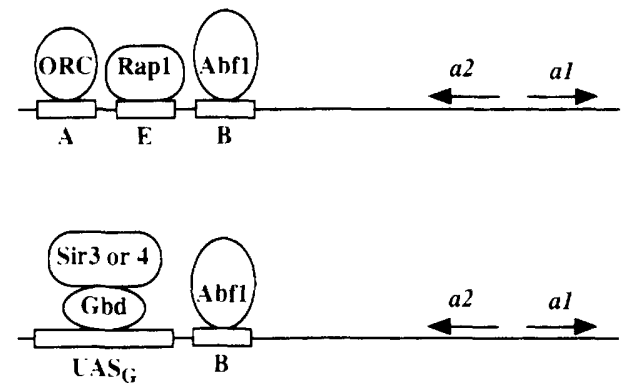

B

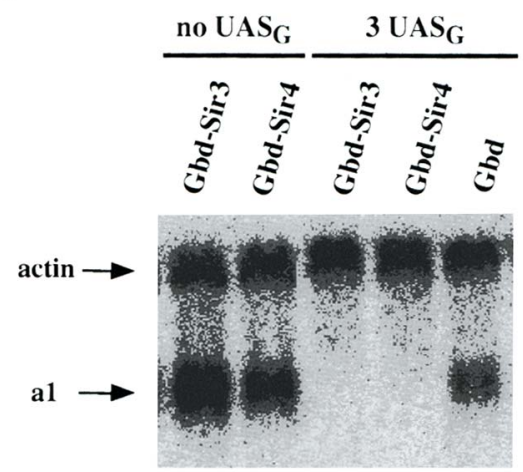

Figure 1. Targeted silencing by Gbd-Sir3 and Gbd-Sir4 hybrid proteins at the silent mating-type locus $H M R$ lacking a functional silencer $(\Delta \mathrm{A} \Delta \mathrm{E})$. (A) Schematic representation of the targeted silencing strategy used in this study. The wild-type $H M R-E$ silencer is shown in the top line. (B) The HMR locus contains the endogenous a1 gene, whose steady-state expression is measured by Northern blotting. Actin message is shown as a control. 
The effects of the two Gbd hybrids were also examined in strains containing a TRP1 reporter gene in place of the normal $a 1$ and $a 2$ genes at $H M R$. In these strains repression is reflected by a reduction in the ability to form colonies on medium lacking tryptophan (Sussel and Shore 1991). Figure 2 shows the effect of $\mathrm{G}_{\mathrm{BD}}-\mathrm{Sir} 3$ and $\mathrm{G}_{\mathrm{BD}}-\mathrm{Sir} 4$ in the three different mutant silencer contexts $(\Delta \mathrm{A} \Delta \mathrm{E}, \Delta \mathrm{E} \Delta \mathrm{B}$, or $\Delta \mathrm{A} \Delta \mathrm{E} \Delta \mathrm{B})$ with or without $\mathrm{UAS}_{\mathrm{G}}$ sites. With both hybrids, the ability to form colonies on medium lacking tryptophan is reduced $>10^{4}$-fold. Nonetheless, there is a clear difference observed between the two double mutant strains and the complete silencer deletion. In the double-mutant silencer strains (where either the $H M R-E$ A or B sites remain) silencing is particularly strong, as judged by the absence, or near absence, of growth on synthetic complete $(\mathrm{SC})$-tryptophan plates even at the lowest cell dilution $\left(\sim 10^{5}\right.$ cells per spot). In contrast, cell growth is seen up to the second dilution when either hybrid is targeted to the complete silencer deletion. The ability of the two Gbd-Sir hybrids to establish silencing is remarkably similar in these three different $H M R-E$ mutant contexts. Consistent with the results from the HMRa strains, the Gbd control plasmid failed to establish silencing and the two Gbd-Sir hybrids require the $\mathrm{UAS}_{\mathrm{G}}$ sites at the mutated silencers to function.

\section{Silencer Targeted

Protein

$$
\underline{\Delta A} \Delta E
$$

$\begin{aligned} \text { 3xUAS }_{\mathrm{G}} & {\left[\begin{array}{c}\text { Gbd } \\ \text { Gbd-Sir3 } \\ \text { Gbd-Sir4 }\end{array}\right.} \\ \text { no UAS }_{\mathrm{G}} & {\left[\begin{array}{c}\text { Gbd-Sir3 } \\ \text { Gbd-Sir4 }\end{array}\right.}\end{aligned}$

- TRP

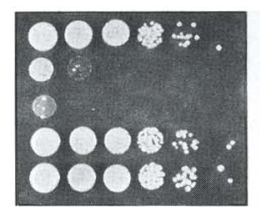

\section{$\underline{\Delta E \Delta B}$}
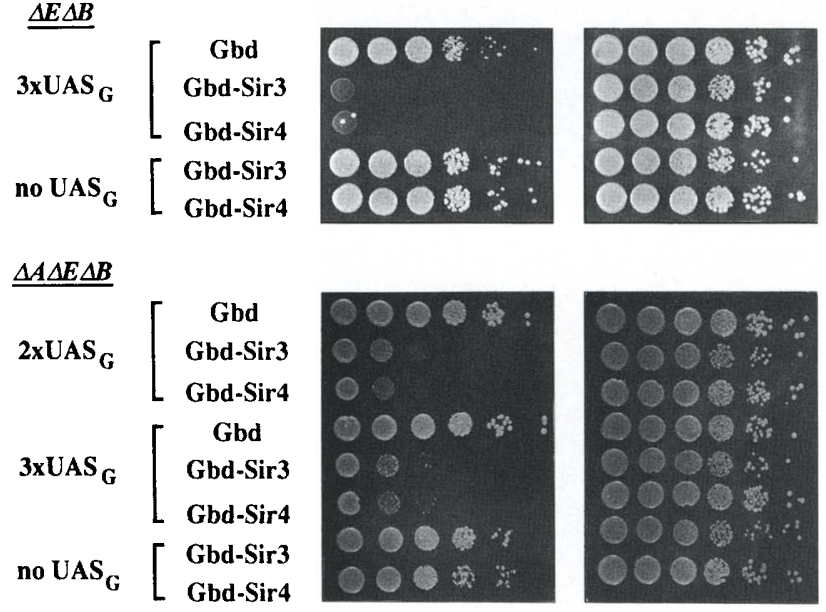

Figure 2. Targeted silencing of an hmr::TRP1 reporter by GbdSir3 and Gbd-Sir4 hybrid proteins with different HMR-E silencer deletions. Silencing is measured by comparing the ability of cells to grow in the absence (-TRP) and presence (+TRP) of tryptophan. Each row consists of spots representing 5- $\mu$ l aliquots from a set of 10 -fold serial dilutions of a liquid culture.

\section{Targeted \\ Protein}
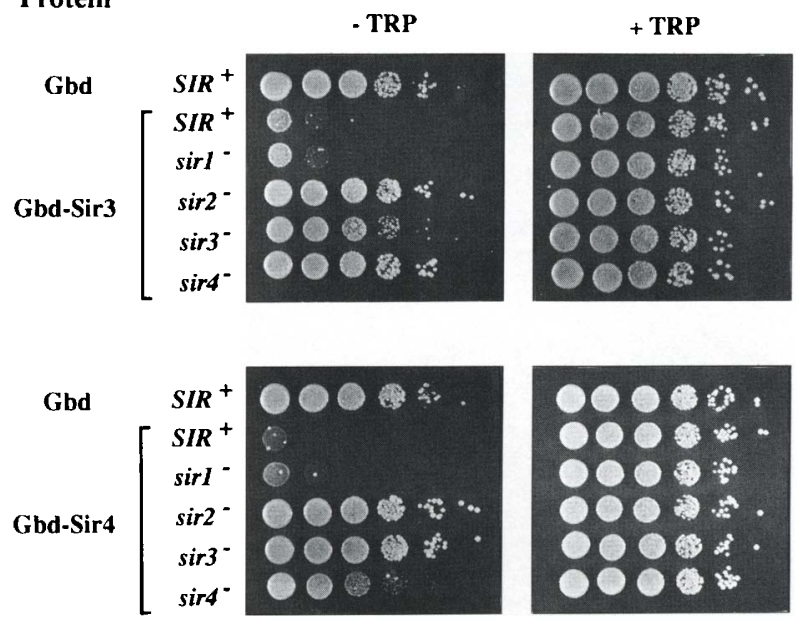

Figure 3. Gbd-Sir3- and Gbd-Sir4-mediated silencing depends on SIR2, SIR3, and SIR4, but not SIR1. The assays were performed as described in Fig. 2.

Silencing by Gbd-Sir3p and Gbd-Sir4p requires SIR2, SIR3, and SIR4 but not SIR1

To determine whether Gbd-Sir3p and Gbd-Sir4p silencing resembles normal silencing at $H M R$, their dependence on $S I R$ gene function was examined in a series of derivatives of the $\triangle \mathrm{A} \Delta \mathrm{E}:: 3 \times \mathrm{UAS}_{\mathrm{G}} h m r:: T R P 1$ reporter strain in which individual $S I R$ genes were mutated by gene disruption. As shown in Figure 3, targeted silencing by either hybrid is unaffected by mutation of SIR1. In contrast, repression by Gbd-Sir3p or Gbd-Sir4p is completely lost in a sir2 reporter strain. Likewise, silencing by Gbd-Sir3p is abolished completely by mutation of SIR4, as is silencing by Gbd-Sir4p in a sir3 mutant. Silencing by Gbd-Sir3p is compromised severely by mutation of SIR3, as indicated by the TRP1 reporter assay. In the sir 3 mutant, colony formation in the absence of tryptophan is reduced only by $\sim 50 \%$, compared to the $>10^{4}$ fold drop observed in the SIR wild-type strain. However, silencing by Gbd-Sir4p in a sir 4 mutant is affected much less severely, as the majority of cells in the culture $(>90 \%)$ still fail to form colonies on the plates lacking tryptophan, and those that do grow very slowly.

\section{Targeting of Sir $3 p$ or Sir $4 p$ enhances} telomeric silencing

To test the effect of Gbd-Sir3p and Gbd-Sir4p hybrids on telomere position effect, we used a strain (Lev8) with four $\mathrm{UAS}_{\mathrm{G}}$ sites downstream of a $U R A 3$ reporter gene placed near an artificial telomere created at the $A D H 4$ locus on the left arm of chromosome VII (Fig. 4A; Gottschling et al. 1990). An isogenic control strain (Lev7) contained the same telomeric URA3 gene but no $\mathrm{UAS}_{\mathrm{G}}$ sites. Three plasmids, expressing Gbd alone, Gbd-Sir $3 p$, or Gbd-Sir4p were transformed into these strains, and the transformants were then assayed for the ability to 
Marcand et al.

\section{A telomere VII L}
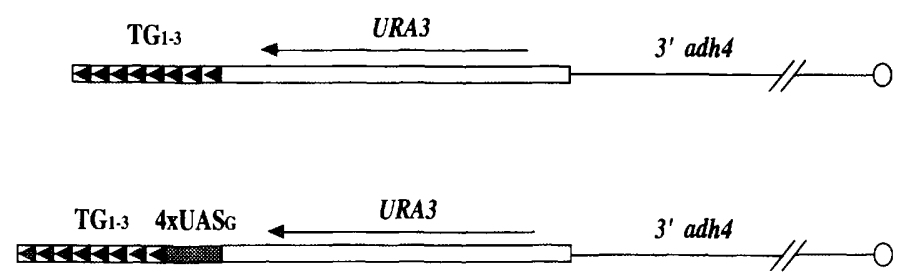

B $\mathrm{ADH4}$

Figure 4. Schematic representation of the different URA3-marked loci used in this study. (A) The structure of the chromosome VII-L telomere in strains Lev7 and Lev8, with and without $\mathrm{UAS}_{\mathrm{G}}$ sites, respectively. The formation of the telomere deletes the 5' half of the ADH4-coding sequence. The orientation of the telomere repeat sequence is represented by successive arrowheads. $(B)$ The structure of the $A D H 4$ locus in strain Levl13. The URA3 marker is inserted downstream (centromere-proximal) of the $A D H 4$ gene. The physical distance from the adjacent telomere is indicated. $(C)$ The structure of the LYS2 locus, in strains Lev98 $\left(4 \times \mathrm{UAS}_{\mathrm{G}}\right.$ sites) and Lev100 (4+2× $\mathrm{UAS}_{\mathrm{G}}$ sites) on the top line, and strains Lev116-Lev119 on the bottom line. Tel and leT refer to a 270-bp telomeric repeat (TEL270) inserted in either orientation. The URA3 marker is inserted in the $3^{\prime}$ half of the LYS2-coding sequence and is transcribed in the opposite direction. The physical distance from the adjacent telomere of chromosome II-R is indicated.

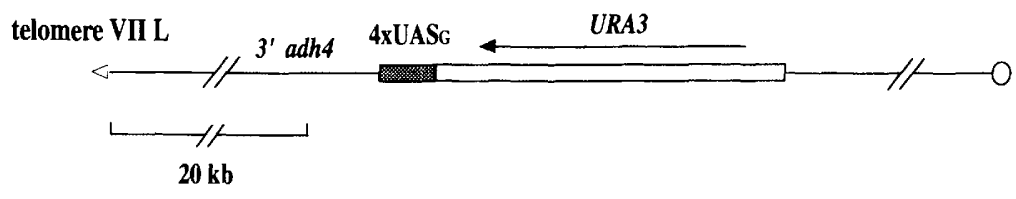

C LYS2
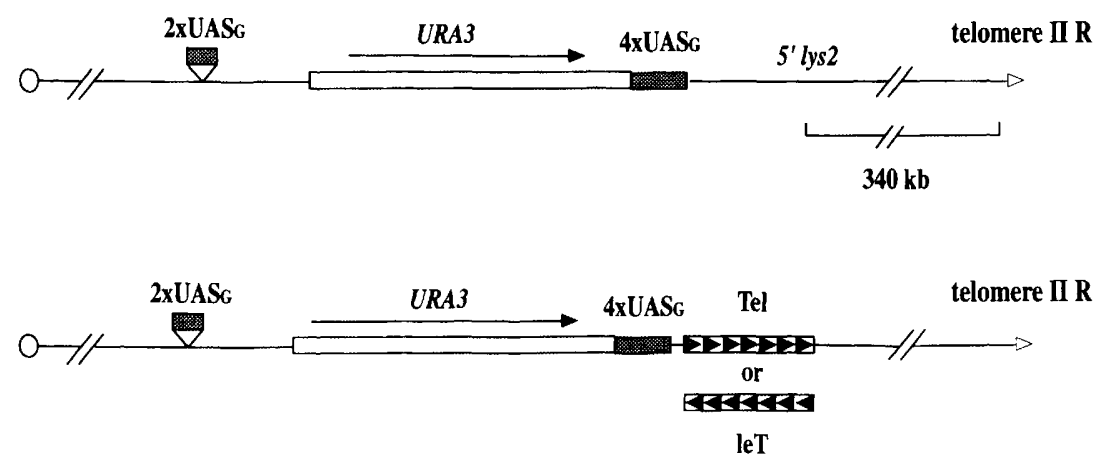

grow on plates containing 5-fluoro-orotic acid (5-FOA), which kills cells expressing the $U R A 3$ gene, or on plates lacking uracil (Table 1).

The Gbd alone control yielded $46 \%$ FOA $^{\mathrm{R}}$ colonies $172 \% \mathrm{Ura}^{+}$colonies) in Lev8, and $60 \% \mathrm{FOA}^{\mathrm{R}} 155 \%$ $\mathrm{Ura}^{+}$) in Lev7, suggesting a slight derepressing effect attributable to the presence of $\mathrm{UAS}_{\mathrm{G}}$ sites and the binding of Gbd. In the absence of telomeric $\mathrm{UAS}_{\mathrm{G}}$ sites, the GbdSir3p hybrid derepresses the telomere, as indicated by a drop to $11 \%$ FOA $^{\mathrm{R}}$ (and a rise to $75 \% \mathrm{Ura}^{+}$cells). In contrast, Gbd-Sir4p expression caused a slight improvement of telomeric silencing in this strain (see below). More important, in the strain that contains telomeric UAS $_{\mathrm{G}}$ sites, both Gbd-Sir3p and Gbd-Sir4p enhance telomeric repression of URA3 significantly, compared with the Gbd alone control. This enhancement is partic- ularly dramatic with Gbd-Sir4p; virtually all the cells became FOA ${ }^{\mathrm{R}}$. After 4 days at $30^{\circ} \mathrm{C}$, only very few cells were able to grow on medium lacking uracil, forming minicolonies. With Gbd-Sir3p, the proportion of FOA ${ }^{\mathbf{R}}$ colonies rose to $73 \%$, almost a sevenfold improvement compared to the strain without telomeric $\mathrm{UAS}_{\mathrm{G}}$ sites expressing this hybrid.

Gbd-Sir3p and Gbd-Sir4p silencing was also examined in two derivatives of the tel::4× $\mathrm{UAS}_{\mathrm{G}}:: U R A 3::$ adh4 strain in which either SIR3 or SIR4 were mutated by gene disruption. In $\operatorname{sir} 3$ and $\operatorname{sir} 4$ mutants, telomeric silencing is lost (Aparicio et al. 1991). Consistent with the results obtained at $H M R, \mathrm{Gbd}-\mathrm{Sir} 3 \mathrm{p}$ or Gbd-Sir4p failed to establish silencing in $\operatorname{sir} 4$ or $\operatorname{sir} 3$ mutant cells, respectively (Table 1). The situation in the corresponding sir mutant cells was also similar to that observed at 
Table 1. Gbd-Sir3 and Gbd-Sir4 enhance silencing at telomere VII-L

\begin{tabular}{|c|c|c|c|c|c|c|c|}
\hline \multirow[b]{2}{*}{$\mathrm{UAS}_{\mathrm{G}}$} & \multicolumn{3}{|c|}{$\mathrm{SIR}^{+}$} & \multicolumn{2}{|c|}{$\Delta \operatorname{sir} 3$} & \multicolumn{2}{|c|}{$\Delta \operatorname{sir} 4$} \\
\hline & $\begin{array}{c}0 \\
{\left[\mathrm{FOA}^{\mathrm{R}}\left(\mathrm{Ura}^{+}\right)\right]}\end{array}$ & & 4 & 0 & 4 & 0 & 4 \\
\hline Gbd & $60(55)^{\mathrm{a}}$ & 46 & $(72)^{a}$ & $<10^{-4}$ & $<10^{-4}$ & $<10^{-4}$ & $<10^{-4}$ \\
\hline Gbd-Sir3 & $11(75)^{\mathrm{a}}$ & 73 & $(37)^{a}$ & $<10^{-4}$ & $<10^{-4}$ & $<10^{-4}$ & $<10^{-4}$ \\
\hline Gbd-Sir4 & $66(33)^{\mathrm{a}}$ & 100 & $(.3)^{a, b}$ & $<10^{-4}$ & $<10^{-4}$ & $.074\langle 100\}^{\mathrm{a}}$ & $82(31)^{a}$ \\
\hline
\end{tabular}

Gbd is expressed from pSB362, Gbd-Sir3 is from spl31, and Gbd-Sir4 is from sp138. All of the reporter strains contain the URA3 immediately adjacent to a telomere created at the $A D H 4$ locus on chromosome VII-L, with or without an intervening UAS cassette (Gottschling et al. 1990; Chien et al. 1993). SIR ${ }^{+}$strains are Lev7 $\left(0 \times \mathrm{UAS}_{\mathrm{G}}\right)$ and Lev8 $\left(4 \times \mathrm{UAS}_{\mathrm{G}}\right) . \Delta$ sir3 strains are Lev102 $\left(0 \times \mathrm{UAS}_{\mathrm{G}}\right)$ and Lev103 $\left(4 \times \mathrm{UAS}_{\mathrm{G}}\right)$, and $\Delta$ sir4 strains are Lev104 $\left(0 \times \mathrm{UAS}_{\mathrm{G}}\right)$ and Lev105 $\left(4 \times \mathrm{UAS}_{\mathrm{G}}\right)$.

${ }^{a}$ The percentage of $5-$ FOA $^{\mathrm{R}}$ cells and the percentage of $\mathrm{Ura}^{+}$cells were calculated by averaging three samples.

${ }^{b}$ Cells grew slowly on media lacking uracil, forming minicolonies after 4 days at $30^{\circ} \mathrm{C}$.

HMR. In sir3 mutant cells, Gbd-Sir3p failed to complement the telomeric silencing defect $\left(<10^{-4} \mathrm{FOA}^{\mathrm{R}}\right.$ cells $)$, even in the presence of $\mathrm{UAS}_{\mathrm{G}}$ sites at the marked telomere. This result suggests that the Gbd-Sir3p hybrid protein may fail to function as a constituent of silent chromatin, instead acting only to initiate telomeric silencing. (This conclusion is consistent with the dominant-negative effect of Gbd-Sir3p on telomeric silencing in wild-type cells; see above.) In contrast to the results with Gbd-Sir3p in a sir3 mutant, Gbd-Sir4p was able to complement partially the telomere silencing defect caused by a sir 4 mutation in a strain lacking telomeric $\mathrm{UAS}_{\mathrm{G}}$ sites (a rise from $<10^{-4}$ to $0.07 \% \mathrm{FOA}^{\mathrm{R}}$ colonies, compared with $66 \%$ in a SIR4 wild-type strain expressing Gbd-Sir4p). Furthermore, in a sir4 mutant strain with $\mathrm{UAS}_{\mathrm{G}}$ sites at the telomere, Gbd-Sir4p restored a high level of resistance to 5-FOA, reflecting strong repression of the telomeric URA3 gene. These results suggest that Gbd-Sir4p retains some degree of native Sir $4 p$ function, and indicate that in strains in which GbdSir $4 p$ is the only functional version of Sir $4 p$, silencing at a telomere without $\mathrm{UAS}_{\mathrm{G}}$ sites is limited by some defect in the action of Gbd-Sir4p at the telomere (silencer) itself.

Targeting of Sir3p or Sir $4 p$ restores telomeric silencing in rapl mutant cells

The results described above indicate that Gbd-Sir3p and Gbd-Sir4p hybrids, when targeted to a telomere, can significantly improve repression there. However, these experiments do not address the question of whether these hybrids are by themselves sufficient to establish repression at a telomere, where a carboxy-terminal silencing "domain" of Raplp (amino acids 667-827) is normally required (Kyrion et al. 1993; Liu et al. 1994; Moretti et al. 1994; Buck and Shore 1995). Therefore, we tested the effect of Gbd-Sir3p and Gbd-Sir4p hybrids on telomeric repression in rap1 mutant cells where the silencing domain of Raplp has been deleted from amino acids 670807 (rap1 $1670-807)$. This mutation abolishes completely transcriptional repression of a telomeric URA3 gene, as indicated by full sensitivity of the strain to 5-FOA (Table 2).

In these rap1 mutant cells, and in presence of telomeric $\mathrm{UAS}_{\mathrm{G}}$ sites, the expression of Gbd-Sir3p or GbdSir4p (but not Gbd alone) restored resistance to 5-FOA and lowered the proportion of $\mathrm{Ura}^{+}$cells (Table 2). However, targeted silencing induced by Gbd-Sir3p or GbdSir $4 p$ at a telomere is slightly weaker in a rap1 mutant than in a wild-type cell, as revealed by a lower proportion of FOA $^{\mathrm{R}}$ colonies. Nonetheless, targeted silencing by Gbd-Sir4p in the rap1 mutant exceeds the level of native silencing at the same marked telomere in a RAP1 wildtype strain $\left(92 \%\right.$ versus $\left.66 \% \mathrm{FOA}^{\mathrm{R}}\right)$. These results indicate that targeted silencing by the Gbd-Sir hybrids is independent of a functional Raplp silencing domain, but that these hybrids (particularly Gbd-Sir $4 p$ ) can act synergistically with wild-type Raplp to establish very stable repression at a telomere.

\section{Action of Gbd-Sir3p and Gbd-Sir4p at two loci not normally subject to silencing}

The experiments described above indicate that GbdSir3p and Gbd-Sir4p can establish transcriptional silencing at $H M R$ and at a telomere, two loci where silencing normally occurs in the cell. Is the targeting of Sir3p and

Table 2. Gbd-Sir3 and Gbd-Sir4 restore silencing at telomere in rapl $\Delta 670-807$ mutant cells

\begin{tabular}{lll}
\hline UAS $_{\mathrm{G}}$ & 0 & 4 \\
\hline Gbd & $<10^{-4}$ & $<10^{-4}$ \\
Gbd-Sir3 & $<10^{-4}$ & $33(66)^{\mathrm{a}}$ \\
Gbd-Sir4 & $<10^{-4}$ & $92(25)^{\mathrm{a}, \mathrm{b}}$ \\
\hline
\end{tabular}

The RAP1 wild-type allele, expressed from pRAP1-Sup4-0 in Lev7 $\left(0 \times \mathrm{UAS}_{\mathrm{G}}\right)$ and Lev8 $\left(4 \times \mathrm{UAS}_{\mathrm{G}}\right)$, has been replaced by a rap1 $\triangle 670-807$ mutant allele expressed from sp18.

${ }^{a}$ The percentage of $5-\mathrm{FOA}^{\mathrm{R}}$ cells and the percentage of $\mathrm{Ura}^{+}$ cells were calculated by averaging three samples.

${ }^{b}$ Cells grew slowly on media lacking uracil, forming minicolonies after 7 days at $30^{\circ} \mathrm{C}$. 
Sir $4 p$ sufficient to establish silencing at loci that are not normally silenced? To answer this question, we tested the hybrid proteins at two other positions in the genome, the $A D H 4$ locus $\sim \sim 20 \mathrm{~kb}$ from the telomere on the left arm of chromosome VII), and the LYS2 locus (approximately in middle of chromosome II, $\sim 360 \mathrm{~kb}$ from the II-R telomere).

To determine the repressive activity of Gbd-Sir3p and Gbd-Sir4p at $A D H 4$, we used strain Lev113, in which a $U R A 3$ reporter gene with four downstream $U_{A S}$ sites has been placed adjacent to the $A D H 4$ gene (Fig. 4B). Lev1 13 is fully sensitive to $5-\mathrm{FOA}$, indicating that $U R A 3$ is expressed normally at this position, as expected (Renauld et al. 1993). This strain was then transformed with three plasmids, expressing either Gbd alone, GbdSir3p, or Gbd-Sir4p, and assayed for 5-FOA resistance and growth on plates lacking uracil (Table 3). The expression of Gbd-Sir4p induced strong repression of $U R A 3$, as indicated by an average of $57 \% \mathrm{FOA}^{\mathrm{R}}$ in these cells. The Gbd-Sir3p hybrid caused a weaker silencing effect, as indicated by the appearance of $2.5 \%$ of $\mathrm{FOA}^{\mathrm{R}}$ cells. The Gbd alone control failed to repress, and in an isogenic strain lacking $U_{A S}$ sites, URA3 remained derepressed in the presence of Gbd-Sir3p or Gbd-Sir $4 p$ (data not shown).

To test the effect of Gbd-Sir3p and Gbd-Sir4p at an internal (nontelomeric) locus, we constructed strain Lev98, in which the same URA3 reporter gene with four downstream $\mathrm{UAS}_{\mathrm{G}}$ sites is inserted within the LYS2 gene on chromosome II (Fig. 4C). Lev98 by itself, or transformed with a plasmid expressing Gbd alone, is fully sensitive to 5-FOA, indicating that URA3 is expressed normally at this position (Table 3). Gbd-Sir3p failed to induce any apparent silencing on $U R A 3$ at this position, as a transformant of Lev98 expressing this hybrid still failed to grow on plates containing 5-FOA ( Table 3). However, Gbd-Sir4p caused weak repression of $U R A 3$ in this strain, as indicated by a small proportion of FOA $^{\mathrm{R}}$ colonies $(0.5 \%$; Table 3$)$.

Table 3. Action of Gbd-Sir3 and Gbd-Sir4 at two loci not normally subiect to silencing

\begin{tabular}{llll}
\hline & \multirow{2}{*}{$\begin{array}{l}\text { LDH4 } \\
\text { UAS }\end{array}$} & $(4)$ & \multicolumn{2}{c}{ LYS2 } \\
\cline { 3 - 4 } & $(4)$ & $<10^{-4}$ & $4+2$ \\
\hline Gbd & $<10^{-4}$ & $<10^{-4}$ & $<10^{-4}$ \\
Gbd-Sir3 & $2.5(92)$ & $.51(100)^{\mathrm{a}}$ & $5.7(95)^{\mathrm{a}}$ \\
Gbd-Sir4 & $57(39)^{\mathrm{a}, \mathrm{b}}$ & &
\end{tabular}

The strain with four $\mathrm{UAS}_{\mathrm{G}}$ sites inserted at $A D H 4$ is Lev113. The strains with four or a cassette of $\mathrm{UAS}_{\mathrm{G}}$ sites inserted at LYS2 are Lev98 and Lev100, respectively. The control strains lacking $\mathrm{UAS}_{\mathrm{G}}$ sites at $A D H 4$ and LYS2 (Lev112 and Lev96, respectively) are fully sensitive to 5-FOA in the presence of GbdSir3 or Gbd-Sir4.

${ }^{\mathrm{a}}$ The percentage of $5-\mathrm{FOA}^{\mathrm{R}}$ cells and the percentage of $\mathrm{Ura}^{+}$ cells were calculated by averaging three samples.

bells grew slowly on media lacking uracil, forming minicolonies after 4 days at $30^{\circ} \mathrm{C}$.
In an attempt to improve this poor silencing at the LYS2 locus, we created a new strain (Lev100) with two more $\mathrm{UAS}_{\mathrm{G}}$ sites inserted $500 \mathrm{bp}$ upstream of the URA3 promoter. In this strain, Levl00, URA3 is flanked by a set of $\mathrm{UAS}_{\mathrm{G}}$ sites, two upstream of the promoter, and four sites downstream of the gene (Fig. $4 \mathrm{C}$ ). In the presence of Gbd-Sir4p, the two new $\mathrm{UAS}_{\mathrm{G}}$ sites caused an 11 -fold increase in the proportion of FOA $^{\mathrm{R}}$ colonies (from $0.5 \%$ to $5.7 \%$ ), but failed to cause repression in the presence of Gbd-Sir3p (Table 3).

\section{Mutation of the Rap1p carboxyl terminus improves Sir $3 p$ and Sir $4 p$ targeted silencing at an internal site, but not near a telomere}

We were curious as to why targeted silencing of URA3 at the LYS2 locus on chromosome II appears to be so much weaker than that which occurs at or near the telomere on the left arm of chromosome VII. One possibility that we considered is that the assembly of silent chromatin at LYS2 is limited by the availability of Sir proteins, which might be sequestered at telomeres. This idea is supported by previous studies (Buck and Shore 1995) demonstrating that telomeres can compete with $H M R$ for limiting silencer factors (Sir $4 \mathrm{p}$ and perhaps others). Furthermore, cytological observations suggest that Sir3p and $\operatorname{Sir} 4 \mathrm{p}$ are concentrated at telomeres in wild-type strains but not in strains in which telomeric repression is abolished by a mutation that deletes the Raplp carboxy-terminal silencing domain (Palladino et al. 1993; Cockell et al. 1995).

Therefore, we tested the effect of the rap1 $\triangle 670-807$ mutation on Gbd-Sir targeted silencing at both $A D H 4$ and LYS2. Similar to what we found for silencing at the artificial chromosome VII-L telomere, targeted silencing of $U R A 3$ at $A D H 4$ was slightly weakened by the rap1 mutation, although this effect may be significant only in the case of Gbd-Sir4p-mediated repression /compare the proportion of $\mathrm{Ura}^{+}$cells in Tables 3 and 4). However, we observed a significant and opposite effect on the action of Gbd-Sir3p and Gbd-Sir4p at LYS2 in a rap1 $1 \Delta 670-807$ mutant strain. In cells expressing Gbd-Sir $4 p$ in the presence of either four $U_{A S}$ sites (4) near URA3 or the flanking cassettes of $\mathrm{UAS}_{\mathrm{G}}$ sites $(4+2)$, the rap1 1670 807 mutation caused a fivefold increase in the proportion of FOA ${ }^{\mathrm{R}}$ colonies (and a significant decrease in the proportion of $\mathrm{Ura}^{+}$colonies). In the strain in which $U R A 3$ is flanked by cassettes of $\mathrm{UAS}_{\mathrm{G}}$ sites, the rap1 $1 \Delta 70-807$ mutation actually allowed detectable silencing by GbdSir3p, although this repression is still weak $10.009 \%$ FOA $^{\mathrm{R}}$.

\section{Internal telomeric repeats boost Gbd-Sir3p and Gbd-Sir4p silencing at the LYS2 locus in a Rap1p-dependent manner}

The experiments described above indicate that the rap1 $1670-807$ mutation, which abolishes telomere position effect, improves targeted silencing by both GbdSir3p and Gbd-Sir4p at the nontelomeric LYS2 locus, but not at the $A D H 4$ locus, which is only $\sim 20 \mathrm{~kb}$ from the 
Table 4. At the internal locus LYS2, but not at the telomeric locus ADH4, Gbd-Sir3 and Gbd-Sir4 activity is improved in rapl mutant cells

\begin{tabular}{|c|c|c|c|c|c|c|}
\hline \multirow[b]{2}{*}{$\mathrm{UAS}_{\mathrm{G}}$} & \multicolumn{2}{|c|}{$A D H 4$} & \multicolumn{4}{|c|}{ LYS2 } \\
\hline & 4 & $\Delta / w t^{a}$ & 4 & $\Delta / w t^{a}$ & $4+2$ & $\Delta / w t^{a}$ \\
\hline Gbd & $<10^{-4}$ & N.A. & $<10^{-4}$ & N.A. & $<10^{-4}$ & N.A. \\
\hline Gbd-Sir3 & $1.9(97)^{\mathrm{b}}$ & 0.76 & $<10^{-4}$ & N.A. & $.009(100)^{\mathrm{b}}$ & $>90$ \\
\hline Gbd-Sir4 & $52(65)^{\mathrm{b}}$ & 0.91 & $2.6(96)^{\mathrm{b}}$ & 5.1 & $26 \quad|63|^{\mathrm{b}}$ & 4.6 \\
\hline
\end{tabular}

The data shown here are from strains containing a RAP1 carboxy-terminal deletion, all of which were generated from the parent strains (Table 3) by replacement of the pRAPl-Sup4-0 plasmid with spl8, which expresses the rap1 $6670-807$ mutant allele.

${ }^{\mathrm{a}}$ The ratio is the percentage of $5-\mathrm{FOA}^{\mathrm{R}}$ cells with the rap1 mutant allele divided by the percentage of 5 -FOA ${ }^{\mathrm{R}}$ cells with the RAP1 wild-type (wt) allele (see Table 3). (N.A.) Not applicable.

${ }^{\mathrm{b}}$ The percentage of $5-\mathrm{FOA}^{\mathrm{R}}$ cells and the percentage of $\mathrm{Ura}^{+}$cells were calculated by averaging three samples.

chromosome VII-L telomere. One possible explanation for this effect might be that the larger distance of LYS2 from a telomeric sequence limits silencing, and that this limitation is reduced by abolishing telomeric silencing through mutation of the Raplp carboxyl terminus. To address this question, we created derivatives of the Lev98 and Lev100 strains in which a telomere repeat sequence $\left(\mathrm{C}_{1-3} \mathrm{~A}\right)$ of $270 \mathrm{bp}$ (TEL270) is inserted in either orientation at $L Y S 2$, adjacent to the four $\mathrm{UAS}_{\mathrm{G}}$ sites and the URA3 reporter gene (Fig. $4 \mathrm{C}$ ). The new strains (Lev116-Lev119) are fully sensitive to 5-FOA, indicating that the internal telomeric sequence is too short to act itself as a silencer, as expected (Stavenhagen and Zakian 1994). However, when Gbd-Sir4p is expressed in these cells, in the presence of four $\mathrm{UAS}_{\mathrm{G}}$ sites or the flanking cassettes of $\mathrm{UAS}_{\mathrm{G}}$ sites, the internal telomeric sequence increased the proportion of FOA $^{\mathrm{R}}$ colonies by an average of 36 -fold or 9-fold, respectively (and decreased the proportion of $\mathrm{Ura}^{+}$cells; see Table 5). Furthermore, in strains in which $\mathrm{UAS}_{\mathrm{G}}$ cassettes flank $U R A 3(4+2)$, the internal telomeric repeats had a dramatic effect on the silencing activity of Gbd-Sir3p, as indicated by $>1 \%$ FOA $^{\mathrm{R}}$, an increase of $>10^{4}$-fold (cf. Tables 3 and 5). The orientation of the telomeric sequence relative to the $U R A 3$ gene does not seem to affect significantly its ability to boost the silencing induced by Gbd-Sir3p and Gbd-Sir4p.

Because the telomeric sequence inserted at LYS2 con- tains 14 potential Raplp-binding sites (Gilson et al. 1993|, we tested its boosting effect on Gbd-Sir3p and Gbd-Sir $4 p$ targeted silencing in a rap1 $\Delta 670-807$ mutant background. In cells expressing Gbd-Sir3p or Gbd-Sir4p and in presence of the $4 \times \mathrm{UAS}_{\mathrm{G}}$ cassette or the two $\mathrm{UAS}_{\mathrm{G}}$ cassettes flanking URA3, and the 270-bp telomeric sequence, the rap1 $\triangle 670-807$ mutation returns the proportion of $\mathrm{FOA}^{\mathrm{R}}$ colonies within twofold of the levels observed in isogenic rap1 $\Delta 670-807$ strains lacking the telomeric insert (Table 5, cf. Table 4). These results indicate that the augmentation of silencing by internal telomeric sequence is fully dependent on the Raplp silencing domain, and suggest that the boosting results from interactions between this domain of Raplp and the Sir3 and Sir4 proteins (Moretti et al. 1994).

\section{Discussion}

\section{The role of Sir3p and Sir4p in silencing}

We have shown that direct recruitment of Sir $3 p$ or Sir $4 p$ to the chromosome through the Gbd can establish transcriptional silencing on a adjacent gene. The dependence of this targeted silencing on SIR2, SIR3, and SIR4 function indicates that it is bona fide silencing rather than a nonspecific effect on transcription. Sir3p and Sir $4 p$ have been proposed previously to be constituents of silent chromatin in yeast. Hecht et al. (1995) demonstrated

Table 5. At the internal locus LYS2, improvement of Gbd-Sir3 and Gbd-Sir4 silencing by internal telomeric repeats requires the Rap1p silencing domain

\begin{tabular}{|c|c|c|c|c|c|c|c|c|}
\hline \multirow{3}{*}{$\begin{array}{l}\text { UAS }_{\mathrm{G}} \\
\text { orientation }\end{array}$} & \multicolumn{4}{|c|}{$R A P 1 \mathrm{wt}$} & \multicolumn{4}{|c|}{ rap $1 \Delta 670-807$} \\
\hline & \multicolumn{2}{|c|}{4} & \multicolumn{2}{|c|}{$4+2$} & \multicolumn{2}{|c|}{4} & \multicolumn{2}{|c|}{$4+2$} \\
\hline & Tel & leT & Tel & leT & Tel & leT & Tel & leT \\
\hline$\overline{\text { Gbd }}$ & $<10^{-4}$ & $<10^{-4}$ & $<10^{-4}$ & $<10^{-4}$ & $<10^{-4}$ & $<10^{-4}$ & $<10^{-4}$ & $<10^{-4}$ \\
\hline Gbd-Sir3 & $<10^{-4}$ & $<10^{-4}$ & $1.5(95)^{\mathrm{a}}$ & $.14(97)^{\mathrm{a}}$ & $<10^{-4}$ & $<10^{-4}$ & $.015(100)^{\mathrm{a}}$ & $.016(100)^{\mathrm{a}}$ \\
\hline Gbd-Sir4 & $20(66)^{a}$ & $17(90)^{\mathrm{a}}$ & $44(62)^{a}$ & $55(41)^{\mathrm{a}}$ & $5.8(96)^{\mathrm{a}}$ & $1.6(99)^{\mathrm{a}}$ & $14 \quad(88)^{a}$ & $17 \quad(90)^{*}$ \\
\hline
\end{tabular}

The four strains Lev115-Lev119 are described in Table 6. The Tel and leT orientations of the TEL270 insert are described in Fig. 4C. The two control strains with a TEL270 insert in two different orientations and without $\mathrm{UAS}_{\mathrm{G}}(\mathrm{Levl14}$ and Lev115) are fully sensitive to 5-FOA in the presence of Gbd-Sir3 or Gbd-Sir4.

${ }^{\mathrm{a}}$ The percentage of $5-\mathrm{FOA}^{\mathrm{R}}$ cells and the percentage of $\mathrm{Ura}^{+}$cells were calculated by averaging four samples. 
that both Sir3p and Sir4p can interact with the aminoterminal tails of the histones $\mathrm{H} 3$ and $\mathrm{H} 4$, and inferred from this that silencing results from the polymerization of these Sir proteins along the chromatin fiber. If this model is correct, our results suggest that the localization of a small number of either Sir3p or Sir $4 p$ molecules to a site on the chromosome is sufficient to initiate the polymerization of these proteins along the chromatin, through a network of Sir-Sir interactions (Chien et al. 1993; Moretti et al. 1994), in the absence of a functional silencer element. Taken together, these studies suggest two distinct roles for the Sir3 and Sir4 proteins in silencing: (1) as constituents of the repressed chromatin and (2) as nucleation sites for initiating the assembly of silenced domains. The failure of the Gbd-Sir3p hybrid to complement a SIR3 mutation provides indirect support for this model. We suggest that this hybrid is specifically defective in the ability to function as a component of repressed chromatin, presumably because of the fusion of Gbd to the amino terminus of Sir3p, but is still able to nucleate the assembly of Sir3p/Sir4p complexes along the chromatin.

The recruitment of Sir3p and Sir $4 p$ can establish transcriptional silencing, but do the $H M$ silencers and the telomeres silence by recruiting $\operatorname{Sir} 3 p$ and Sir $4 p$ ? It has been shown previously that a carboxy-terminal region of Raplp interacts with Sir3p and Sir4p in the two-hybrid system, and with Sir3p directly in vitro (Moretti et al. 1994). A deletion of this interacting domain (amino acids 679-827) abolishes telomeric repression and derepresses $H M R$ in contexts where the HMR-E silencer is completely dependent on the Raplp-binding site for repression (Kyrion et al. 1993; Moretti et al. 1994). Fused to a Gbd, this region of Raplp establishes transcriptional silencing when targeted to $H M R$ or a telomere (Buck and Shore 19951; S. Marcand and D. Shore, unpubl.). Furthermore, point mutations in RAP1 that have been isolated on the basis of a loss of silencing generally result in a weakening of the Raplp-Sir3p interaction in the twohybrid system (S. Buck and D. Shore, unpubl.). Taken together, these results strongly support the idea that Raplp works at $H M$ silencers and at telomeres by recruiting a Sir3p-Sir $4 p$ complex by direct protein-protein interactions with its carboxyl terminus (Moretti et al. 1994). The fact that direct recruitment of Sir3p and Sir $4 p$ brings about silencing further supports this model and suggests that the ability of Raplp to interact with these silencing proteins may be sufficient to explain its essential role in this process.

Targeting of Sir $4 p$ to a telomere greatly increases the efficiency of telomeric silencing, to the point where the linked $U R A 3$ reporter gene is repressed in virtually all of the cells within a culture. Previous studies have shown that the unusual mutation rap1-12 results in a similar improvement in telomeric silencing and an increase in the Raplp-Sir $4 p$ interaction, as measured by the twohybrid system (Buck and Shore 1995). These two independent observations suggest that the efficiency of recruitment of Sir $4 \mathrm{p}$ to a telomere may determine, at least in part, the probability that silencing will be established at that telomere. It is possible, then, that the difference in strength between telomeric and $H M$ silencing reflects a difference between the telomere and the $H M$ silencers in the ability to recruit Sir4p.

\section{Do telomeres function as regulators of chromosomal silencing?}

We observed a strict correlation between the strength of targeted silencing by Sir3p and Sir $4 p$ and proximity to a telomere. Silencing established by Gbd-Sirlp and Gbd/ Raplp hybrids displays the same correlation (S. Marcand, unpubl.). These results fit well with a growing body of evidence that the strength of silencer elements is itself position dependent, in that they appear to work better when placed at or near telomeres. For example, Thompson et al. (1994) have noted that silencing at HMR is helped by an adjacent telomere on chromosome III (at a distance of $\sim 25 \mathrm{~kb}$ ), and others have shown that the $H M L$ and $H M R$ silencers are less effective at the centromere-proximal MAT locus than when at their normal telomere-proximal sites (Shei and Broach 1995). In addition, the strength of $\mathrm{C}_{1-3} \mathrm{~A}$-based silencing is improved significantly by proximity to a telomere (Stavenhagen and Zakian 1994). Finally, the $H M L$ silencers do not function at LYS2, and this defect can be corrected by the creation of a new telomere at a distance of $12 \mathrm{~kb}$ from the LYS2 locus (L. Maillet, C. Boscheron, M. Gotta, S. Marcand, E. Gilson, and S.M. Gasser, in prep.).

A particularly striking observation reported here is that targeted silencing at a nontelomeric site (LYS2) is improved by deletion of the Raplp carboxyl terminus, whereas at the same time silencing at or near a telomere is either slightly weakened or unaffected. Because targeted silencing by Sir3p and Sir4p at LYS2 does not involve Raplp directly (to our knowledge there are no Raplp-binding sites at this locus), we presume that the effect of the rap1د670-807 mutation is indirect, and most likely attributable to events occurring at telomeres, which contain a high density of Raplp-binding sites within the $\mathrm{C}_{1-3} \mathrm{~A}$ repeats. We propose that the improvement of silencing at LYS2 in the rap1 $1670-807$ mutant is attributable to an increase in the nontelomeric concentration of silencing factors (Sir3p and Sir $4 p$, and perhaps other proteins) resulting from a release of these factors from telomeres, where they are normally concentrated through interactions with telomere-bound Rap1p (Moretti et al. 1994) and the resultant spreading of silent chromatin from these sites (Renauld et al. 1993). Five lines of evidence support this hypothesis. First, silencing is known to be extremely sensitive to the gene dosage of SIR3 and SIR4. Diploid strains containing only one functional copy of the SIR4 gene display unstable repression at $H M R$ (Sussel et al. 1993), whereas extra copies of SIR4 can suppress various silencing defects at HMR (Sussel and Shore 1991; Buck and Shore 1995). At telomeres, extra copies of SIR 3 increase the spreading of silent chromatin along the chromosome (Renauld et al. 1993). Second, immunolocalization studies (Palladino et al. 1993) indicate that Sir3p and Sir4p colocalize with Raplp at the telomeres and are concentrated and sequestered in a 
small number of foci at the periphery of the nucleus. This observation suggests that the local concentration of silencing factors inside the nucleus of a wild-type cell is variable, depending on the distance from one of these telomeric foci (Fig. 5A). Third, in rap1 mutant cells where the silencing domain of Raplp has been deleted, Sir3p appears to become delocalized in the nucleus, suggesting that its concentration may increase at nontelomeric sites, relative to wild-type strains (Cockell et al. 1995) (Fig. 5B). Fourth, efficient function of the $H M L$ silencers can be restored at LYS2 when Sir3p and $\operatorname{Sir} 4 p$ are overexpressed, a situation that mimics the proposed release of these factors from telomeres in our rap1 1670 807 strains (L. Maillet, C. Boscheron, M. Gotta, S. Marcand, E. Gilson, and S.M. Gasser, in prep.). Finally, an internal telomeric sequence, without being a silencer itself, boosts targeted silencing established by Gbd-Sir3p, Gbd-Sir4p, Gbd-Sirlp, or Gbd/Raplp, an effect that requires the silencing domain of Raplp (Table 5; S. Marcand, unpubl.). We propose that telomeric sequences act at LYS2 through unstable Sir3p-Rap1p and Sir4p-Raplp interactions, which, although by themselves are unable to establish silencing, are sufficient to increase the local concentration of these factors at the site of the internal repeats (Fig. 5C). Similar long-range "boosting" effects on native silencers by either a telomere, telomeric repeat sequences, or individual Raplp-binding sites have been observed at HML and LYS2 (Boscheron et al. 1996; L. Maillet, C. Boscheron, M. Gotta, S. Marcand, E. Gilson, and S.M. Gasser, in prep.). An alternative explanation is that the internal telomeric repeat interacts with a real telo-mere and thereby moves the internal site to within one of the telomeric foci, where silencing factor concentration is high, a situation equivalent to a subtelomeric position (Fig. 5C). Taken together, these data support the notion that silencing is very sensitive to the local concentration of silencing factors, and that the telomeres play a major role in determining silencing factor availability within the nucleus. In this view the action of telomeres is dual; negative for the whole genome by titrating away silencing factors, and positive for the subtelomeric regions by increasing locally the concentration of these factors.

Even in cells where the Raplp carboxyl terminus is absent and telomeric silencing is abolished, we still found targeted silencing by Gbd-Sir3p and Gbd-Sir $4 p$ to
A

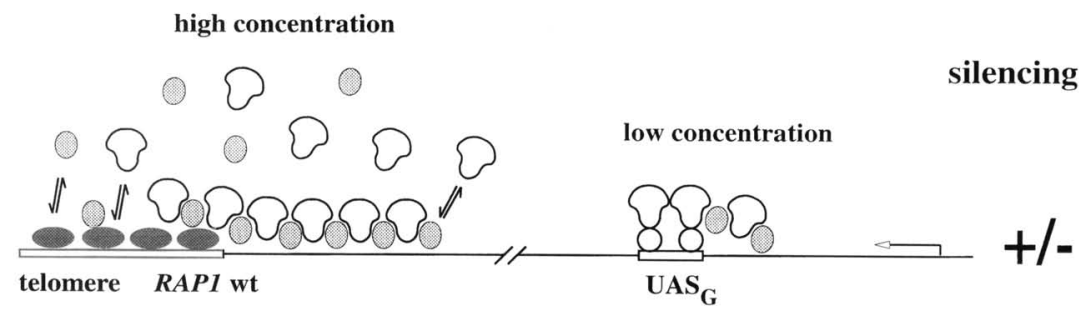

B

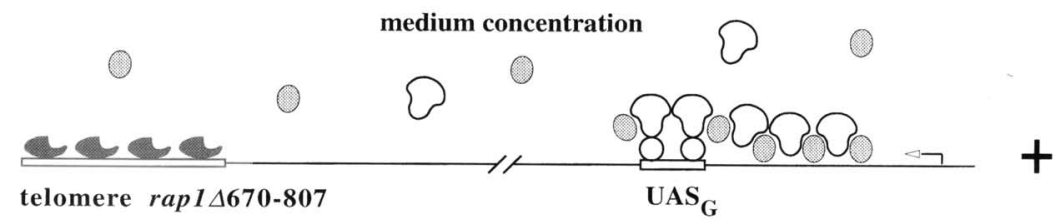

C

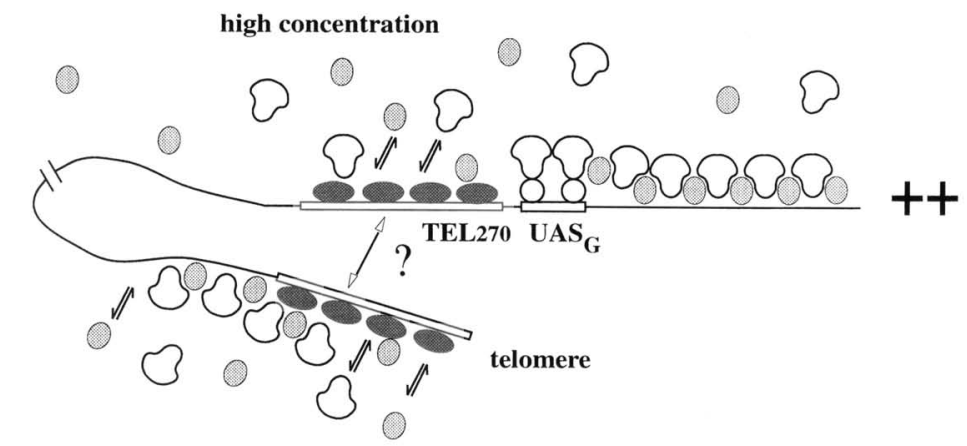

Rap1p $\operatorname{rap1p} \Delta 670-807$ Sir3p

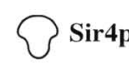

$\{$ Gbd-Sir4
Figure 5. A model for the concentration and sequestration of silencing factors by telomeres, and its effect on the establishment of silencing at internal chromosomal sites. A telomere is represented at the left, bound by several Raplp molecules (dark shaded oval). (Right) An internal (nontelomeric) locus is represented with several $\mathrm{UAS}_{\mathrm{G}}$ sites bound to Gbd-Sir4 hybrid molecules. The relative strength of targeted silencing at this internal position is represented at the far right. $(A)$ In wild-type cells, telomeres recruit Sir3p and Sir $4 p$ molecules through direct Raplp-Sir interactions, and initiate the polymerization of Sir proteins along the adjacent chromatin, titrating most of the Sir molecules away from the rest of the nucleus. At an internal position, the resultant low concentration of silencing factors compromises the strength of targeted silencing by Gbd-Sir4 hybrids. $(B)$ In rap1 $1670-807$ mutant cells, the loss of SirRaplp interactions abolishes telomeric silencing and liberates Sir $3 p$ and Sir $4 p$ from the telomeres, resulting in a more uniform concentration of Sir $3 p$ and Sir $4 p$ throughout the nucleus. At an internal position, this higher concentration of silencing factors improves targeted silencing. $|C|$ In wild-type cells, the proximity of a short telomeric sequence might improve targeted silencing at an internal position, through (unstable) Sir-Raplp interactions that cause a local increase in Sir $3 p$ and Sir $4 p$ concentration, above that created by the rap 1 $1670-807$ mutation in $B$. An alternative, but not mutually exclusive, explanation is that the telomeric repeat interacts with a real telomere, and moves the internal site to an environment with a high concentration of silencing factors. These two possibilities are presented together. 
be stronger at a telomere or in the proximity of a telomere (at $A D H 4$ ) than at a more internal position on another chromosome (LYS2). Although there may be somewhat trivial explanations for the extent of the quantitative differences we observe, for example that the LYS2 locus contains or is flanked by strong promoters that mitigate against the establishment of silent chromatin (Aparicio and Gottschling 1994), other possibilities should be considered. For example, the localization of telomeres to the nuclear periphery in yeast (Klein et al. 1992) may help to promote the establishment of silent chromatin. Alternatively, the late replication of telomeres and telomere-proximal regions (McCarroll and Fangman 1988) could favor the establishment of silencing, which appears to occur during the $\mathrm{S}$ phase of the cell cycle (Miller and Nasmyth 1984).

The biological role of telomeric silencing in yeast is still unclear. Some genes naturally positioned in the proximity of a telomere do not appear to be regulated by the SIR genes. For example, the expression of SUC and $M A L$ family genes, all located next to or between subtelomeric repeats, is not affected by a loss of telomeric silencing (S. Marcand and D. Shore, unpubl.). The unstable and epigenetic nature of telomeric silencing suggests too that the function of telomeres may not be to regulate gene expression locally, although more work is clearly needed to resolve this question. On the basis of the results reported here and previously (Buck and Shore 1995), we propose instead a novel role for telomeres in regulating the susceptibility of the genome to transcriptional silencing by serving as a reservoir or molecular sink for Sir proteins, thereby controlling their effective concentration at nontelomeric loci. We suggest that this function of telomeres is important to avoid the establishment of silent chromatin at inappropriate positions, and to favor silencing at the two subtelomeric silent $H M$ loci. In this regard, we note that a recent study of senescence in yeast (as measured by the average number of divisions a cell will undergo before ceasing to divide) suggests a role for some form of Sir regulation in aging, as a specific allele of $S I R 4$ correlates a delay in aging with a loss of telomeric silencing (Kennedy et al. 1995). This increase in life span may be a fortuitous consequence of an indiscriminate increase in silencing throughout the genome, attributable to a breakdown in its control by telomeres. Alternatively, it might reveal a natural example of regulated silencing in yeast. It will be particularly interesting, especially with regard to the second hypothesis, to identify the putative "aging" genes that are subjected to Sir regulation.

In Drosophila, repression induced by repeated sequences is stronger in the proximity of the centromeric heterochromatin, suggesting that centromeres in Drosophila play the role of telomeres in yeast in organizing the susceptibility of the genome to heterochromatinization (Dorer and Henikoff 1994). It is possible that the existence of a heterochromatin organizer is a conserved characteristic of the cell in different organisms. In humans, successive somatic cell divisions cause a progressive shortening of telomeres until cells enter into senes- cence and stop dividing (for review, see Harley 1995). If one assumes some similarity between yeast and human telomeres, then telomere shortening in human cells may release analogs of Sir3p and Sir $4 p$ and affect expression of genes in trans, in much the same way a rap1 mutation improves targeted silencing at an internal locus, or progressive telomere shortening improves silencing of the HMR locus (Buck and Shore 1995) in yeast. In this model, cells enter senescence when the concentration of released factors reaches a threshold sufficient to turn off genes essential for cell cycle progression.

In summary, our results highlight the dynamic nature of silencing in yeast and its extreme sensitivity to the concentrations of factors that play an essential role in its initiation and propagation. One strong inference from these results is that the concentration of Sir proteins within the nucleus varies according to the proximity of a given site from a telomere, in a manner that can be regulated by Raplp and telomere length. It seems possible, if not likely, that this phenomenon is important not only to prevent the inappropriate silencing of genes throughout the chromosome, but to control the expression of $H M$ mating-type loci (Buck and Shore 1995; L. Maillet, C. Boscheron, M. Gotta, S. Marcand, E. Gilson, and S.M. Gasser, in prep.) and as yet unidentified genes that might be normally subjected to some degree of Sir repression. Finally, we believe that this perspective may have important implications for the way in which telomere metabolism affects gene regulation in mammalian cells.

\section{Materials and methods}

\section{Yeast strains and methods}

The yeast strains used in this study are all derivatives of W303lB (HML $\alpha$ MAT $\alpha$ HMRa ade2-1 ura3-1 his3-11, 15 leu2-3, 112 trpl-1 can 1-100) or its isogenic MATa relative W303-1A, and are listed in Table 6. All gene disruptions or replacements (Rothstein 1991) used to generate these strains were confirmed by Southern blotting. Growth and manipulation of yeast strains were done according to standard procedures (Rose et al. 1990). Lev7 and Lev8 are derived from a cross between YLS85 and YDS631 or YDS634, respectively. Lev102 and Lev103 are derived from a cross between YLS1 26 and Lev7 or Lev8, respectively. Lev104 and Lev105 are derived from a cross between YLS134 and Lev7 or Lev8, respectively. Lev112, Lev113, Lev96, Lev98, Lev100, and Lev114-119 result from the transformation of YLS85 with the linearized plasmids spl63, sp164, sp107, spl09, sp156, and spl72-177, respectively.

Assays for silencing using the $h m r:: T R P 1$ reporter were performed by spotting 10-fold serial dilutions of cultures grown in appropriate synthetic selective medium as described /Sussel and Shore 1991). Determination of the proportion of $5-\mathrm{FOA}^{\mathrm{R}}$ cells and $\mathrm{Ura}^{+}$cells was done as follows: independent colonies were resuspended in water, diluted to an appropriate concentration, and spread on SC-His, SC-His-Ura and fresh $\mathrm{SC}-\mathrm{His}+5$ FOA plates (0.8 gram/liter of 5-FOA). The number of colonies were counted after 4 days at $30^{\circ} \mathrm{C}$ for the RAP1 wild-type strains, and after 7 days for the rap1 $\Delta 670-807$ strains. Each percentage represents the average of three or more samples. The standard deviation between the different samples was significantly higher with the strains displaying a smaller proportion of $\mathrm{FOA}^{\mathrm{R}}$ colonies; for a mean $>30 \%$, between $30 \%$ and $3 \%$, or $<3 \%$, the ratio standard deviation/mean was respectively $<0.30$, between 0.23 and 0.72 , or between 0.30 and 1.08 . 
Table 6. Yeast strains

\begin{tabular}{|c|c|c|}
\hline Strain & Genotype & Source \\
\hline W303-1B & HML $\alpha$ MAT $\alpha$ HMRa ade2-1 ura3-1 his3-11,15 leu2-3,112 trp1-1 can1-100 & Thomas and Rothstein (1989) \\
\hline YSB46 & W303-1B $\Delta \mathrm{A} \Delta \mathrm{E}:: 3 \times \mathrm{UAS}_{\mathrm{G}}$ gal4::LEU2 & Buck and Shore (1995) \\
\hline YSB68 & YSB62 except $\Delta \mathrm{A} \Delta \mathrm{E}$ & Buck and Shore (1995) \\
\hline YSB1 & W303-1B $\triangle \mathrm{A} \Delta \mathrm{E}$ hmr::TRP1 gal4::LEU2 & Buck and Short (1995) \\
\hline YSB2 & YSBl except $\Delta \mathrm{A} \Delta \mathrm{E}:: 3 \times \mathrm{UAS}_{\mathrm{G}}$ & Buck and Shore (1995) \\
\hline YSB64 & YSBl except $\Delta \mathrm{E} \Delta \mathrm{B}$ & Buck and Shore (1995) \\
\hline YSB35 & YSBl except $\Delta \mathrm{E} \Delta \mathrm{B}:: 3 \times \mathrm{UAS}_{\mathrm{G}}$ & Buck and Shore (1995) \\
\hline YSB43 & YSBl except $\Delta \mathrm{A} \Delta \mathrm{E} \Delta \mathrm{B}$ & Buck and Shore $(1995)$ \\
\hline YSB39 & YSBl except $\Delta \mathrm{A} \Delta \mathrm{E} \Delta \mathrm{B}:: 2 \times \mathrm{UAS}_{\mathrm{G}}$ & Buck and Shore (1995) \\
\hline YSB41 & YSBl except $\Delta \mathrm{A} \Delta \mathrm{E} \Delta \mathrm{B}:: 3 \times \mathrm{UAS}_{\mathrm{G}}$ & Buck and Shore (1995) \\
\hline YSBl60 & YSB2 except $\operatorname{sir} 1:: U R A 3$ & Buck and Shore (1995) \\
\hline RS1042 & YSB2 except sir2::URA3 & Chien et al. (1993) \\
\hline RS1061 & YSB2 except sir3::URA3 & Chien et al. (1993) \\
\hline RS1067 & YSB2 except sir4::URA3 & Chien et al. (1993) \\
\hline YLS85 & W303-1B MATAa rap1::LEU2 pRapl-Sup4-0 & Sussel and Shore (1991) \\
\hline YLS126 & W303-1B $\triangle B h m r:: T R P 1$ sir3::LEU2 & Sussel and Shore (1991) \\
\hline YLS134 & W303-1B $\triangle B h m r:: T R P 1$ sir4::LEU2 & Sussel and Shore (1991) \\
\hline YDS631 & W303-1B adh4::URA3-telVII-L & Chien et al. (1993) \\
\hline YDS634 & W303-1B adh4::URA3-4 $\times$ UAS $_{\mathrm{G}^{-}}$telVII-L & Chien et al. (1993) \\
\hline Lev7 & YDS631 except rap1::LEU2 pRAPl-Sup4-0 & this study \\
\hline Lev8 & YDS634 except rap1::LEU2 pRAP1-Sup4-0 & this study \\
\hline Lev 102 & Lev7 except sir3::LEU2 & this study \\
\hline Lev103 & Lev8 except sir3::LEU2 & this study \\
\hline Levl04 & Lev7 except sir4::LEU2 & this study \\
\hline Levl05 & Lev8 except $\operatorname{sir} 4:: L E U 2$ & this study \\
\hline Levl12 & YLS85 except adh4::URA3 & this study \\
\hline Levl13 & YLS85 except adh4::URA3 $4 \times \mathrm{UAS}_{\mathrm{G}}$ & this study \\
\hline Lev96 & YLS85 except lys2::URA3 & this study \\
\hline Lev98 & YLS85 except lys2::URA3-4 $4 \mathrm{UAS}_{\mathrm{G}}$ & this study \\
\hline Lev 100 & YLS85 except lys2::URA3 $(4+2) \times \mathrm{UAS}_{\mathrm{G}}$ & this study \\
\hline Lev 114 & YLS85 except lys2::URA3-TEL270 (Tel) & this study \\
\hline Levl15 & YLS85 except lys2::URA3-TEL270 (leT) & this study \\
\hline Levl 16 & YLS85 except lys2::URA3-4 $\times \mathrm{UAS}_{\mathrm{G}}-\mathrm{TEL} 270\langle$ Tel $\rangle$ & this study \\
\hline Lev1 17 & YLS85 except lys2::URA3-4 × $\mathrm{UAS}_{\mathrm{G}}-\mathrm{TEL} 270\{\mathrm{leT}\}$ & this study \\
\hline Levl 18 & YLS85 except lys2::URA3-(4+2) $\times$ UAS $_{\mathrm{G}}-\mathrm{TEL} 270(\mathrm{Tel})$ & this study \\
\hline Lev1 19 & YLS85 except lys2::URA3- $(4+2) \times \mathrm{UAS}_{\mathrm{G}}-\mathrm{TEL} 270(\mathrm{leT})$ & this study \\
\hline
\end{tabular}

\section{Plasmid DNAs}

The rap 1 $\triangle 670-807$ allele was created by joining two $R A P 1$ fragments with a $X$ hoI linker at each end, creating a deletion with a Xhol linker in the middle. The new rap1 fragment $\mid E c o$ RIXbaI) was ligated into EcoRI- and XbaI-cut pRS313 (HIS3 CENVI) to give plasmid PM585. The HIS3 gene of this new plasmid was disrupted as follows: PM585 was cut with NdeI, end-filled with Klenow polymerase, and religated to give plasmid sp 18. Plasmid pSB362 (Gbd alone) is based on pRS313 (HIS3 CENVI) and contains sequences encoding Gbd fused to the RAP1 promoter (Buck and Shore 1995). The two plasmids spl31 (encoding Gbd-Sir3p) and spl38 (encoding Gbd-Sir4p) were constructed by ligating a $\mathrm{HpaI}$ fragment from pCTC70 and pCTC4l (Chien et al. 1993), respectively, into HpaI- and XbaIcut pSB362.

To insert URA3 in the proximity of the ADH4 locus, we used a genomic fragment isolated as follows: the plasmid pADH4UCA (Gottschling et al. 1990) was digested with HindIII and SphI (deleting the $3^{\prime}$ end of $A D H 4$ ), end-filled using Klenow polymerase, and religated to give plasmid sp190. The $A D H 43^{\prime}$ fragment (HindIII-SphI filled in) was reinserted into NotI-cut, Klenow-treated sp190. This new plasmid (sp92) was digested with Sall and transformed into strain W303-1B. The genomic
DNA of this new strain was digested with PstI, religated and transformed into Escherichia coli. The rescued plasmid (spl60) contains a 5-kb genomic sequence extending from the $3^{\prime}$ half of $A D H 4$ toward the centromere. The integrating plasmids /spl63 and sp 164) used to place the $U R A 3$ gene at $A D H 4$ were constructed by ligating HindIII-BamHI fragments containing $U R A 3$ (from pADH4UCA) or $U R A 3-4 \times \mathrm{UAS}_{\mathrm{G}}$ (from D1724; Chien et al. 1993) into HindIII- and BamHI-cut sp160. The two plasmids were integrated after digestion with EcoRI.

The integrating plasmids (sp107 and sp109) used to place the $U R A 3$ gene at LYS2 were constructed by ligating the same HindIII-BamHI fragments containing URA3 or URA3-4X $\mathrm{UAS}_{\mathrm{G}}$ into $\mathrm{pD} 6 \mathrm{P}$ (a pUC vector ligated to a $5-\mathrm{kb}$ genomic fragment including LYS2; Fleig et al. 1986) that was digested with $X$ hol (filled in). A cassette of $\mathrm{UAS}_{\mathrm{G}}$ was created by inserting $2 \times$ $\mathrm{UAS}_{\mathrm{G}}$ (a BamHI-BglII fragment from D1716; Chien et al 1993) into the BamHI site of spl09 (spl56). The TEL270 sequence (a filled-in HindIII-EcoRI fragment from pLTel; Gilson et al. 1994) was inserted into the recreated Xhol (filled in) site of sp107, sp109, and sp156, creating the plasmids spl72 (Tel), sp173 (leT), spl74 (Tel), spl75 (leT), spl76 (Tel), and spl77 (leT), respectively. Tel indicates that the telomeric insert is in the same orientation than in pADH4UCA relative to the URA3 gene, $1 e T$ 
indicates the opposite orientation. All nine plasmids were integrated after digestion with BglII and EcoRI.

\section{RNA analysis}

Total yeast RNA was prepared and analyzed by Northern blotting using standard procedures. HMR a1 mRNA was detected by probing with a random-primed 650 bp XhoI-BglII DNA fragment from plasmid D401 (Xhol linker mutant no. 238; Abraham et al. 1984). The blot was reprobed with a 500-bp EcoRI-HindIII fragment from the actin gene and analyzed with a PhosphorImager (Molecular Dynamics). The range was 14-156 counts.

\section{Acknowledgments}

We thank David Wotton for a critical reading of the manuscript, Serge Gangloff for help and advice, and Susan Gasser and Thierry Laroche for useful discussions at the start of this project. E.G. thanks the Association pour la Recherche Contre le Cancer, Groupement de Recherche et d'Etude sur les Genomes, Ligue Nationale Contre le Cancer, and Association Francaise de Lutte Contre la Mucoviscidose for financial support; D.S. acknowledges the National Institutes of Health (grant GM40094) for financial support.

The publication costs of this article were defrayed in part by payment of page charges. This article must therefore be hereby marked "advertisement" in accordance with 18 USC section 1734 solely to indicate this fact.

\section{References}

Abraham, J., K.A. Nasmyth, J.N. Strathern, A.J.S. Klar, and J.B. Hicks. 1984. Regulation of mating-type information in yeast. J. Mol. Biol. 176: 307-331.

Aparicio, O.M. and D.E. Gottschling. 1994. Overcoming telomeric silencing: A trans-activator competes to establish gene expression in a cell cycle-dependent way. Genes \& Dev. 8: $1133-1146$.

Aparicio, O.M., B.L. Billington, and D.E. Gottschling. 1991. Modifiers of position effect are shared between telomeric and silent mating-type loci in S. cerevisiae. Cell 66: 12791287.

Bell, S.P. and B. Stillman. 1992. ATP-dependent recognition of eukaryotic origins of DNA replication by a multiprotein complex. Nature 357: 128-134.

Bell, S.P., R. Kobayashi, and B. Stillman. 1993. Yeast origin recognition complex functions in transcripton silencing and DNA replication. Science 262: 1844-1849.

Bell, S.P., J. Mitchell, J. Leber, R. Kobayashi, and B. Stillman. 1995. The multidomain structure of Orclp reveals similarity to regulators of DNA replication and transcriptional silencing. Cell 83: 563-568.

Biswas, S.B. and S.B. Biswas. 1990. ARS binding factor I of yeast Saccharomyces cerevisiae binds to sequences in telomeric and nontelomeric autonomously replicating sequences. Mol. Cell. Biol. 10: 810-815.

Boscheron, C., L. Maillet, S. Marcand, M. Tsai-Pflugfelder, S.M. Gasser, and E. Gilson. 1996. Cooperation at a distace between silencers and proto-silencers at the yeast $H M L$ locus. EMBO I. 15: 2184-2195.

Brand, A.H., L. Breeden, J. Abraham, R. Sternglanz, and K. Nasmyth. 1985. Characterization of a "silencer" in yeast: A DNA sequence with properties opposite to those of a transcriptional enhancer. Cell 41: 41-48.

Brand, A.H., G. Micklem, and K. Nasmyth. 1987. A yeast si- lencer contains sequences that can promote autonomous plasmid replication and transcriptional activation. Cell 51: 709-719.

Buchman, A.R., W.J. Kimmerly, J. Rine, and R.D. Kornberg. 1988. Two DNA-binding factors recognize specific sequences at silencers, upstream activating sequences, autonomously replicating sequences, and telomeres in Saccharomyces cerevisiae. Mol. Cell. Biol. 8: 210-225.

Buck, S.W. and D. Shore. 1995. Action of a RAPl carboxy-terminal silencing domain reveals an underlying competition between $H M R$ and telomeres in yeast. Genes \& Dev. 9: 370384 .

Chien, C.-T., P.L. Bartel, R. Sternglanz, and S. Fields. 1991. The two-hybrid system: A method to identify and clone genes for proteins that interact with a protein of interest. Proc. Natl. Acad. Sci. 88: 9578-9582.

Chien, C.-T., S. Buck, R. Sternglanz, and D. Shore. 1993. Targeting of SIRl protein establishes transcriptional silencing at HM loci and telomeres in yeast. Cell 75: 531-541.

Cockell, M., F. Palladino, T. Laroche, G. Kyrion, C. Liu, A.J. Lustig, and S. M. Gasser. 1995. The carboxy termini of Sir4 and Rapl affect Sir3 localization: Evidence for a multicomponent complex required for yeast telomeric silencing. $I$. Cell Biol. 129: 909-924.

Diffley, J.F.X. and J.H. Cocker. 1992. Protein-DNA interactions at a yeast replication origin. Nature 357: 169-172.

Dorer, D.R. and S. Henikoff. 1994. Expansions of transgene repeats cause heterochromatin formation and gene silencing in Drosophila. Cell 77: 993-1002.

Fleig, U.N., R.D. Pridmore, and P. Philippsen. 1986. Construction of LYS2 cartridges for use in genetic manipulation of Saccharomyces cerevisiae. Gene 46: 237-245.

Foss, M., F.J. McNally, P. Laurenson, and J. Rine. 1993. Origin recognition complex $(\mathrm{ORC})$ in transcriptional silencing and DNA replication in S. cerevisiae. Science 262: 1838-1844.

Gilson, E., M. Roberge, R. Giraldo, D. Rhodes, and S.M. Gasser. 1993. Distortion of the DNA double helix by RAPl at silencers and multiple telomeric binding sites. J. Mol. Biol. 231: 293-310.

Gilson, E., T. Muller, J. Sogo, T. Laroche, and S.M. Gasser. 1994. RAPl stimulates single- to double-strand association of yeast telomeric DNA: Implications for telomere-telomere interactions. Nucleic Acids Res. 22: 5310-5320.

Gottschling, D.E., O.M. Aparicio, B.L. Billington, and V.A. Zakian. 1990. Position effect at $S$. cerevisiae telomeres: Reversible repression of pol II transcription. Cell 63: 751-762.

Harley, C.B. 1995. Telomeres and aging. In Telomeres (ed. E.H. Blackburn and C.W. Greider), pp. 247-263. Cold Spring Harbor Laboratory Press, Cold Spring Harbor, NY.

Hecht, A., T. Laroche, S. Strahl-Bolsinger, S.M. Gasser, and M. Grunstein. 1995. Histone $\mathrm{H} 3$ and $\mathrm{H} 4 \mathrm{~N}$ termini interact with SIR3 and SIR4 proteins: A molecular model for the formation of heterochromatin in yeast. Cell 80: 583-592.

Kennedy, B.K., N.R. Austriaco, J. Zhang, and L. Guarente, 1995. Mutation in the silencing gene SIR 4 can delay aging in $\mathrm{S}$. cerevisiae. Cell 80: 485-496.

Kimmerly, W., A. Buchman, R. Kornberg, and J. Rine. 1988. Roles of two DNA-binding factors in replication, segregation and transcriptional repression mediated by a yeast silencer. EMBO J. 7: 2241-2253.

Klein, F., T. Laroche, M.E. Cardenas, J.F.-X. Hofmann, D. Schweizer, and S.M. Gasser. 1992. Localization of RAP1 and topoisomerase II in nuclei and meiotic chromosomes of yeast. J. Cell. Biol. 117: 935-948.

Kurtz, S. and D. Shore. 1991. The RAPl protein activates and silences transcription of mating-type genes in yeast. Genes 
\& Dev. 5: 616-628.

Kyrion, G., K. Liu, C. Liu, and A.J. Lustig. 1993. RAPl and telomere structure regulate telomere position effects in Saccharomyces cerevisiae. Genes \& Dev. 7: 1146-1159.

Laurenson, P. and J. Rine. 1992. Silencers, silencing, and heritable transcriptional states. Microbiol. Rev. 56: 543-560.

Liu, C., X. Mao, and A.J. Lustig. 1994. Mutational analysis defines a C-terminal tail domain of RAPl essential for telomeric silencing in Saccharomyces cerevisiae. Genetics 138: 1025-1040.

Longtine, M.S., N.M. Wilson, M.E. Petracek, and J. Berman. 1989. A yeast telomere binding activity binds to two related telomere sequence motifs and is indistinguishable from RAPl. Curr. Genet. 16: 225-240.

Loo, S., P. Laurenson, M. Foss, A. Dillin, and J. Rine. 1995. Roles of $A B F 1, N P L 3$, and YCL54 in silencing in Saccharomyces cerevisiae. Genetics 141: 889-902.

Louis, E.J., E.S. Naumova, A. Lee, N. Gennadi, and J.E. Haber. 1994. The chromosome end in yeast: Its mosaic nature and influence on recombination dynamics. Genetics 136: 789802.

Mahoney, D.J., R. Marquardt, G.-J. Shei, A.B. Rose, and J.R. Broach. 1991. Mutations in the HML E silencer of Saccharomyces cerevisiae yield metastable inheritance of transcriptional repression. Genes \& Dev. 5: 605-615.

Marshall, M., D. Mahoney, A. Rose, J.B. Hicks, and J.R. Broach. 1987. Functional domains of SIR4, a gene required for position effect regulation in Saccharomyces cerevisiae. Mol. Cell. Biol. 7: 4441-4452.

McCarroll, R.M. and W.L. Fangman. 1988. Time of replication of yeast centromeres and telomeres. Cell 54: 505-513.

Micklem, G., A. Rowley, J. Harwood, K. Nasmyth, and J.F.X. Diffley. 1993. Yeast origin recognition complex is involved in DNA replication and transcriptional silencing. Nature 366: $87-89$.

Miller, A.M. and K.A. Nasmyth. 1984. Role of DNA replication in the repression of silent mating-type loci in yeast. Nature 312: 247-251.

Moretti, P., K. Freeman, L. Coodley, and D. Shore. 1994. Evidence that a complex of SIR proteins interacts with the silencer and telomere-binding protein RAP1. Genes \& Dev. 8: $2257-2269$.

Palladino, F., T. Laroche, E. Gilson, A. Axelrod, L. Pillus, and S.M. Gasser. 1993. SIR3 and SIR4 proteins are required for the positioning and integrity of yeast telomeres. Cell 75: 543-555.

Pillus, L. and J. Rine. 1989. Epigenetic inheritance of transcriptional states in S. cerevisiae. Cell 59: 637-647.

Renauld, H., O.M. Aparicio, P.D. Zierath, B.L. Billington, S.K. Chhablani, and D.E. Gottschling. 1993. Silent domains are assembled continuously from the telomere and are defined by promoter distance and strength, and by SIR3 dosage. Genes \& Dev. 7: 1133-1145.

Rine, J. and I. Herskowitz. 1987. Four genes responsible for a position effect on expression from $H M L$ and $H M R$ in Saccharomyces cerevisiae. Genetics 116: 9-22.

Rose, M.D., F. Winston, and P. Hieter. 1990. Methods in yeast genetics: A laboratory course manual. Cold Spring Harbor Press, Cold spring Harbor, NY.

Rothstein, R. 1991. Targeting, disruption, replacement, and allele rescue: Integrative DNA transformation in yeast. Methods Enzymol. 194: 281-301.

Shei, G.-J. and J.R. Broach. 1995. Yeast silencers can act as orientation-dependent gene inactivation centers that respond to environmental signals. Mol. Cell. Biol. 15: 3496-3506.

Shore, D. 1995. Telomere position effect and transcriptional silencing in the yeast Saccharomyces cerevisiae. In Telomeres (ed. E.H. Blackburn and C.W. Greider), pp. 247-263. Cold Spring Harbor Laboratory Press, Cold Spring Harbor, NY.

Shore, D. and K. Nasmyth. 1987. Purification and cloning of a DNA binding protein from yeast that binds to both silencer and activator elements. Cell 51: 721-732.

Shore, D., D.J. Stillman, A.H. Brand, and K.A. Nasmyth. 1987. Identification of silencer binding proteins from yeast: Possible roles in SIR control and DNA replication. EMBO $J$. 6: $461-467$.

Stavenhagen, J.B. and V.A. Zakian. 1994. Internal tracts of telomeric DNA act as silencers in Saccharomyces cerevisiae. Genes \& Dev. 8: 1411-1422.

Stone, E.M., M.J. Swanson, A.M. Romeo, J.B. Hicks, and R. Sternglanz. 1991. The SIR1 gene of Saccharomyces cerevisiae and its role as an extragenic suppressor of several mating-defective mutants. Mol. Cell. Biol. 11: 2253-2262.

Sussel, L. and D. Shore. 1991. Separation of transcriptional activation and silencing functions of the $R A P 1$-encoded repressor/activator protein 1 : Isolation of viable mutants affecting both silencing and telomere length. Proc. Natl. Acad. Sci. 88: 7749-7753.

Sussel, L., D. Vannier, and D. Shore. 1993. Epigenetic switching of transcriptional states: cis- and trans-acting factors affecting establishment of silencing at the HMR locus in Saccharomyces cerevisiae. Mol. Cell. Biol. 13: 3919-3928.

Thomas, B.J. and R. Rothstein. 1989. Elevated recombination rates in transcriptionally active DNA. Cell 56: 619-630.

Thompson, J.S., L.M. Johnson, and M. Grunstein. 1994. Specific repression of the yeast silent mating locus $H M R$ by an adjacent telomere. Mol. Cell. Biol. 14: 446-445. 


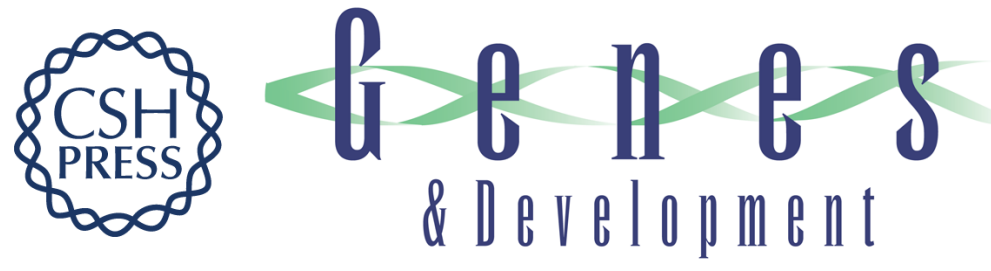

\section{Silencing of genes at nontelomeric sites in yeast is controlled by sequestration of silencing factors at telomeres by Rap 1 protein.}

S Marcand, S W Buck, P Moretti, et al.

Genes Dev. 1996, 10:

Access the most recent version at doi:10.1101/gad.10.11.1297

References This article cites 53 articles, 25 of which can be accessed free at:

http://genesdev.cshlp.org/content/10/11/1297.full.html\#ref-list-1

License

Email Alerting

Service

Receive free email alerts when new articles cite this article - sign up in the box at the top right corner of the article or click here.

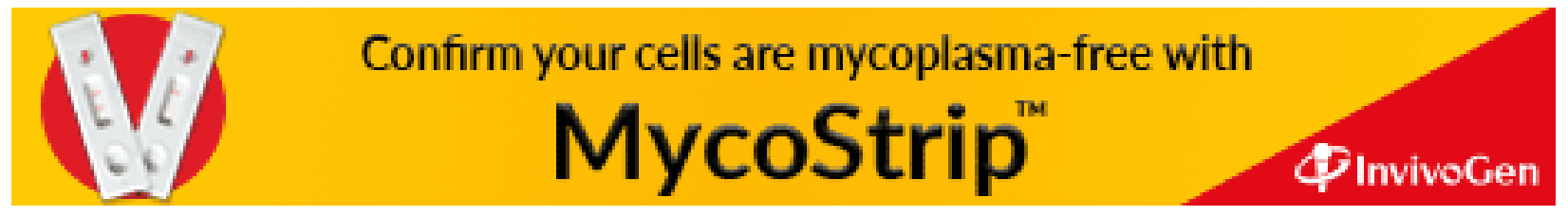

